\title{
Colecionadores e cidadania patrimonial: os agenciamentos de arquivos pessoais em projetos memorialistas locais ${ }^{1}$
}

\author{
José Rogério Lopes \\ Professor Doutor da Universidade do Vale do \\ Rio dos Sinos, São Leopoldo, Brasil \\ jrlopes@unisinos.br \\ Rodrigo Manoel Dias da Silva \\ Professor Doutor da Universidade do Vale do \\ Rio dos Sinos, São Leopoldo, Brasil \\ rodrigods@unisinos.br
}

Resumo $\mathrm{O}$ artigo discute as demandas memorialistas de colecionadores privados projetadas nas agendas políticas de patrimonialização cultural, em abordagem situacional. Desde a descrição de dois casos de colecionamento - um em Canela, RS; outro em São Luiz do Paraitinga, SP -, consideram-se as estratégias e táticas operadas pelos colecionadores, visando a formação de arquivos pessoais, sua digitalização e os agenciamentos dos mesmos sobre as memórias coletivas, desde a perspectiva da cidadania patrimonial. Esta abordagem implica considerar as coleções como bens sociais que produzem modulações nas memórias coletivas locais, pelo estabelecimento de regimes discursivos e regimes de valor, ora em processos de singularização negociados nas redes de interação dos colecionadores, ora em processos de institucionalização das coleções em "dispositivos memorialistas" públicos, como publicações e centros de memória.

Palavras-chaves: Colecionadores, cidadania patrimonial, arquivos, memórias, agenciamentos.

1 Os autores agradecem ao $\mathrm{CNPq}$ o financiamento do projeto cujos dados são aqui parcialmente analisados. 


\section{Apresentação}

Este artigo é um recorte do projeto "Colecionismo, agenciamentos coletivos e patrimônios culturais", realizado desde 2012. O objetivo da pesquisa prevê investigar a potencialização de projetos individuais e coletivos de colecionadores contemporâneos na ressignificação de processos locais de patrimonialização cultural. $O$ foco do projeto são os agenciamentos de atores/colecionadores não institucionalizados, que utilizam mediações tecnológicas e relativizam concepções de autenticidade, memória e identidade, característicos dos tradicionais repertórios coletivos. Buscamos compreender o protagonismo de indivíduos e grupos na constituição contemporânea de coleções, de forma viva e dinâmica, como resultado de interações sociais e processos comunicacionais que possuem agência e elegem aspectos do passado tidos como importantes de serem destacados, de acordo com as identidades e interesses dos atores.

As investigações que se desenvolveram, no quadro da pesquisa, seguiram as orientações gerais da abordagem etnográfica, especificamente da Análise situacional (Van Velsen, 1987), considerando três contextos selecionados: Canela (RS), São Luiz do Paraitinga (SP) e Mariana (MG). ${ }^{2}$ Nestes, identificamos colecionadores (indivíduos ou grupos) e passamos a acompanhar seus empreendimentos identitários de formação de coleções e os agenciamentos que realizavam.

Desde a pergunta inicial da pesquisa (por que as pessoas colecionam coisas?) à definição situacional de um campo relacional entre memórias e patrimônios, que buscou objetivar os agenciamentos coletivos dos colecionadores identificados, uma complexidade de elementos foi se evidenciando. Delimitamos tais agenciamentos desde a concepção de "mapas de orientação social" (Velho, 1987), pela possibilidade que a mesma abriu de estabelecer uma objetivação de quadros de experiência colecionistas e suas variadas lógicas de ação.

As primeiras interpretações dos casos estudados tornaram perceptível a dificuldade de elaborar uma análise global dos mesmos. A opção que orientou os primeiros textos seguiu a lógica de interpretar tais casos segundo alguns perspectivismos que foram se configurando em torno dos mesmos: a correspondência das coleções com ciclos de vida, a negociação de reconhecimentos sociais em torno da formação de repertórios ou arquivos privados, e os processos de singularização de regimes de valor em torno das coleções. Estes textos foram reorganizados e publicados em livro (Lopes, 2017), seguindo a opção de elaborar uma análise geral, cuja trajetória segue de quadros explicativos exploratórios dos atos de colecionamento à definição de quadros de experiência conceituais e, depois, dos situacionais. 
Assim, os quadros de experiências ${ }^{3}$ colecionistas se tornaram os referenciais para o entendimento desta objetivação, o que permitiu evidenciar alguns pressupostos articuladores da análise empreendida. Estes pressupostos permitiram enquadrar alguns referenciais comuns da experiência colecionista, assim como algumas de suas variações. São referenciais comuns: as motivações para colecionar coisas são despertadas no fim da infância, ou na adolescência; a prática colecionista se desenvolve em redes de interações significativas para os indivíduos (que se tornam redes de sociabilidade); as coleções se estruturam em processos de distinção ou estima social (tornando-se bens de marcação simbólica); as interações estabelecidas nesses processos produzem um deslocamento dos registros individuais que motivam o início das coleções para registros coletivos que as mantêm; tornando-se bens de marcação simbólica, as coleções geram uma mudança de valores e referências sobre as coisas colecionadas e produzem idealizações sobre sua publicização; singularizado e legitimado em regimes de valor, o processamento das coleções tende atualmente à digitalização, como forma de constituir repertórios ou arquivos, seja em registros processuais, seja em registros documentais das mesmas. Já as variações se apresentaram nas distintas formações da concepção de arquivo, ou repertório, e seus consequentes agenciamentos operados pelos indivíduos, e nas correlações entre aprendizado colecionista e práticas de educação patrimonial. O caráter situacional dessas variações parece assentar-se na percepção de que,

Depois dos trabalhos, muitos deles notáveis, que analisaram os "bens culturais", o sistema de sua produção, o mapa de sua distribuição e a distribuição dos consumidores nesse mapa, parece possível considerar esses bens não apensas como dados a partir dos quais se pode estabelecer os quadros estatísticos de sua circulação ou constatar os funcionamentos econômicos de sua difusão, mas também como o repertório com o qual os usuários procedem a operações próprias (Certeau, 1994, p. 93).

Esses pressupostos, seguidos de seus enquadramentos, permitiram correlacionar as agências das memórias individuais e grupais em contextos situados de patrimonialização cultural, de forma a poder inferir que as memórias projetadas desde a configuração das coleções como bens são depuradas nas diversas interações estabelecidas pelos colecionadores. Sendo assim, as memórias relacionadas às coleções podem atuar como coisas boas para se pensar, como suportes para "práticas de contar" (os regimes discursivos), ou como referências coletivas legitimadas para a construção da história local (regimes de valor). As duas últimas delimitações conformam o que aqui buscamos configurar como projetos memorialistas

3 Optamos por utilizar a definição de quadros de experiência (frames) de Goffman (2012) porque, distinto dos modelos de pensamento que se formam em conceitos ou paradigmas, na estrutura dos campos científicos, segundo Kuhn (1983), ela define melhor o conjunto de elementos explicativos de um fenômeno que adquirem efetividade cognitiva em uma determinada categoria de aplicação de sentidos, ou quadros de análise. Assim, os quadros de experiência são importantes elementos de distinção de atitudes ou elaborações de conhecimento, em subcampos do conhecimento ou de expertise societária, sendo costumeiramente reconhecidos na literatura acadêmica da Antropologia, por exemplo, como ressignificações de práticas e conceitos de análise. 
locais, pensando que as mesmas possibilitam avançar na objetivação dos agenciamentos coletivos dos colecionadores nos processos contemporâneos de patrimonialização cultural. Supomos, acompanhando Lima Filho (2015), que tais agenciamentos operam modulações do caráter essencialista da memória coletiva agenciada pelo Estado, ao buscar circunscrever o mito da nação e arbitrar padrões de identidade e dispositivos institucionais de políticas culturais. Sobretudo, tais modulações operam sobre esses padrões, primeiro, relativizandoos como modelos históricos para, depois, inscrevê-los situacionalmente em experiências coletivas, e na constituição de arquivos. Esse é o sentido pelo qual Lima Filho (2015, p. 140) afirma que

O reverso do patrimônio tem lugar na cidadania patrimonial, potencializando a cidadania insurgente. Essa última possibilidade não tem sido contemplada pelos autores quando escrevem sobre o patrimônio. Ora, a análise do patrimônio distanciada do mito da nação só é capaz se consideramos o conflito ou a insurgência colada também ao conceito de cidadania. Dessa forma, a ação patrimonial movida pelos atores sociais desenha uma escala cuja mensuração vai do mito da nação à sua resistência/negação assumida por atores sociais que politicamente se situam nas margens, nas fraturas e clivagens, ou seja, em direção a uma ideia de anti-mito da nação.

Assim, tanto a relativização quanto a inscrição situacional dos padrões e modelos identitários ressignificam as memórias nacional e coletiva, tornando a memória um recurso negociado segundo o campo de possibilidades em que os projetos dos indivíduos e grupos se movem, visando constituir suas coleções em bens coletivos. Nesse sentido, as memórias inscritas nos bens colecionados ultrapassam a condição de serem boas para pensar quando se tornam recursos negociados em um campo de projetos patrimoniais, justamente porque "O patrimônio é bom para jogar, caso os atores estejam dispostos a jogar. Caso contrário, o patrimônio será refratado pelos grupos sociais” (Lima Filho, 2015, p. 143).

Trata-se de compreender uma disponibilidade que se projeta dos indivíduos, em exteriorizar seus objetos de coleção num campo de negociação de memórias, mesmo quando tal campo é concebido com um jogo de características maleáveis. É assim que percebemos como a relação entre apego e desapego dos indivíduos com suas coleções se desdobrava em lógicas de ação coletivas, de agir sobre os outros, saindo da inércia de uma ilusão situacional vivida para a refração de uma ilusão coletiva (Lopes, 2017).

Nesse processo, para Lima Filho (2015, p. 144),

$[\ldots]$ a operacionalidade da cidadania patrimonial [...] relaciona engajamento com formas temporais: o presente (capacidade de avaliação), o passado (memória) e futuro (projetos).

A noção de modulação que acoplo ao conceito de cidadania patrimonial permite a resposta desse rompimento inercial de acordo com a biografia pessoal/coletiva do(s) ator(es) alvo das políticas patrimoniais. Biografia atravessada pelas dimensões históricas, econômicas, políticas, de gênero, de raça, de classe e de identidade social. Daí a modulação. 
Nas cidades estudadas, regularmente presenciamos dois ou mais colecionadores discutindo acerca das lembranças relacionadas à autenticidade de um objeto de suas coleções, ou dos acontecimentos locais que eles evocam, enunciando uma frase recorrente: "Você não está lembrando direito!" Nesses diálogos, quem detém o objeto de coleção que incita a discussão geralmente evoca atributos como propriedade e autenticidade para delimitar a consistência e a legitimidade de uma memória correspondente ao mesmo. ${ }^{4}$ Esse é caso de dois colecionadores que apresentaremos: Benedito dos Santos (sitiante e contador de histórias; São Luiz do Paraitinga, SP) e Antônio Olmiro dos Reis (gráfico aposentado; Canela, RS), reconhecidos em suas cidades como guardiões da memória local.

Estes colecionadores instituem dispositivos, projetos ou lugares de memória (Nora, 1993) para publicizar suas coleções na forma de publicações e centros de memória, e supomos aqui que a configuração desses lugares constitui a dimensão estratégica e operacional daquelas modulações. Segundo Certeau (1994, p. 102):

As estratégias são portanto ações que, graças ao postulado de um lugar de poder (à propriedade de um próprio), elaboram lugares teóricos (sistemas e discursos totalizantes), capazes de articular um conjunto de lugares físicos onde as forças se distribuem [...]. Ao menos procuram elas reduzir a esse tipo as relações temporais pela atribuição analítica de um lugar próprio a cada elemento particular e pela organização combinatória dos movimentos específicos a unidades ou a conjuntos de unidades.

Dessa forma, as trajetórias instituintes desses dispositivos permitem reconhecer como os agenciamentos que os atores operam constituem demandas memorialistas de colecionadores privados projetadas nas agendas políticas de patrimonialização cultural.

\section{Quadros de experiência colecionista, memórias e patrimônio}

O primeiro quadro de experiência é o de Benedito dos Santos (Ditão Virgílio, ${ }^{5}$ como é conhecido). Ditão nasceu e cresceu em São Luiz do Paraitinga, ${ }^{6}$ no bairro rural

4 Essa evocação é possível porque uma coleção, pensada como acervo ou arquivo, possui um elemento primordial, que é "seu poder organizador dos vários registros sobre as ações humanas" (Assis, 2017, p. 45). Por outro lado, a discussão acerca da autenticidade de uma memória relacionada ao objeto de coleção remete à discussão de Le Goff (1996) sobre a distinção entre o fundamento do documento (como prova) e do monumento (como memória) para interpretar o passado, e de como o poder é utilizado para a transformação do primeiro no segundo.

5 As entrevistas com Ditão Virgílio foram realizadas em vários momentos, ao longo dos últimos oito anos.

6 Cidade localizada no mar de morros da Serra do Mar, no cone leste do Estado de São Paulo, entre oVale do Paraíba e o litoral norte do estado. Atualmente, o município conta com 10.397 habitantes, segundo informações do sítio oficial da Prefeitura Municipal. Disponível em: <http://www.saoluizdoparaitinga.sp.gov.br/site/>. Acesso em: 26 ago. 2017. 
do Bom Retiro, onde possui um sítio. Atualmente, tem 63 anos e é reconhecido como contador de histórias. ${ }^{7}$

A trajetória de colecionador a memorialista, percorrida por Ditão, inicia com a confluência de algumas experiências, logo na infância. Primeiro, o contato com contadores de história, no mundo rural.

Todos sábados na roça lá, Bom Retiro, Santa Cruz, tinha os contadores de história, muitos contadores de história, era tão gostoso ir na casa deles, porque eles estavam falando também na Folia de Reis. Tinha sete ou oito anos, a gente ia para a casa deles para ouvir eles contarem história, o Bastião Nocêncio, era um dos bons contadores de história, e contava cada história maravilhosa, e era tão bom porque a gente ia para a casa dele e tinha que voltar depois, no escuro.

Após tal contato, o ingresso na escola e o contato com livros de cordel.

[...] eu tinha, para você ter uma ideia, uns sete ou oito anos de idade, e eu estou com 55, e a gente comprava vários cordéis, tinha o Incêndio do Paraná, eu lembro direitinho.

[...] como naquele tempo era difícil nós vir para a cidade, estudava lá com sete, oito, nove anos, na escola do Bom Retiro, e não dava para vir pra cidade, só vinha para comprar os livrinhos e levar lá na roça. E eu fui aprendendo uma coisa interessante, é mais fácil passar uma lição para uma criança em versos do que uma coisa muito grande em prosas, ela decora mais rápido, aprende mais rápido e pensa mais rápido, sabe, fica mais fácil.

O universo das histórias de cordel se complementa, após os primeiros anos escolares, com o ingresso de Ditão na Folia de Reis ${ }^{8}$ do bairro e o contato com o universo das transmissões radiofônicas.

[...] desde criança eu acompanhava a minha mãe, o meu pai, e eles passavam lá em casa [a Folia de Reis], e eu via a situação do palhaço de dançar, e eu adorava aquela coisa de brincar com a criançada. No começo tinha medo, depois a gente vai observando uma dança muito diferente e os versos também que eram falados, muitas vezes falavam aqueles versos, cantoria e falavam dos santos na parede, e todas essas histórias foi interessando. Aí o Zé Leite passava por lá e falava: "Oh Ditão, vamos acompanhar nós". Aí um dia eu lembro que foi lá na fazenda do João Maia, aqui no oriente, a gente ia a pé, a cavalo, tudo mais e ia. Eu fui acompanhando e chegou lá um dos palhaços, que era o Silvio Leite, e ele falou "Ah Ditão, vai no meu lugar". Ele queria me pôr para

7 Ditão possui página no Facebook, além de uma página pessoal, disponível no endereço: <http://www. ditaovirgilio.com.br/p/meu-artesanato.html>. Acesso em: 20 ago. 2017.

8 Há muitas formações de Folias de Reis, um ritual votivo do catolicismo no período natalino. No caso da Folia indicada por Ditão, trata-se de Folia de Reis mineira, com rica tradição de mestres populares hábeis em improvisar versos. Um histórico desta Folia de Reis está elaborado em outro estudo (Lopes, 2007). 
dançar um pouco lá. Eu fui lá, pus a máscara e ele falou "ah faz um versinho", e eu fiz o verso. Daí começou a dançar. E aí eu comecei a gostar, tomar interesse por aquilo lá, porque já tinha né, já estava no sangue, essa coisa da cultura tá no sangue, de ver lá aquele canto maravilhoso da Folia de Reis. [...]

E aí começava aquilo lá, tinha a rádio Nacional de São Paulo, que depois virou Globo, $1100 \mathrm{Khz}$, aquela coisa toda lá, e eu gostava de ouvir as duplas sertanejas cantando, e tinha toda essa coisa dos versos, era Jacó e Jacózinho, Tonico e Tinoco, Ziro e Zalo, Zico e Zelo, era uma leva. Toda segunda-feira era duas duplas ou três no máximo, e era terça-feira, quarta, quinta e sexta, e tinha essa coisa de ouvir esses versos, essas músicas já, e aí eu fui aprendendo, misturando essa coisa do palhaço que eu estava falando, e eu comecei a fazer verso, escrevi nuns cadernos lá.

Esta confluência de experiências, atravessada constantemente pela percepção centrada "nos versos", situa Ditão em um movimento de transição da tradição para a modernidade, em que vários traços da cultura rural foram desaparecendo, ou se transformando.

[...] eu fui aprendendo isso, e essas pessoas foram morrendo e foi acabando, e aí comecei a frequentar São Luís, e aí já fiquei lá com certa idade, vendo alguma coisa de televisão (começou a surgir televisão na época). $\mathrm{Na}$ minha casa só teve eletricidade em 1980, foi a primeira luz elétrica que eu vi na minha casa, na roça era essas usinas de água que batia lá e fazia eletricidade, mas tinha um horário para apagar, e lá em casa nem tinha isso, era lamparina mesmo, e então comecei a vir para a cidade, ouvia algumas histórias aqui na cidade também né, e voltava para roça, e tinha acabado aquela coisa do sábado ir na casa dos contadores de história, uns morrem, outros com a dificuldade de viver na roça mudaram para a cidade, acompanhado dos filhos. E eu senti a vontade, de como a gente vai deixar isso morrer? E eu comecei a ver os versinhos que eu tinha falado lá no começo, os cordéis que tinha aqui para vender e tal, e eu comecei a fazer em verso as histórias que eles contavam.

Nesse momento, Ditão se torna colecionador, não de objetos, mas de histórias, casos, acontecimentos.

[...] porque eu achei assim né, uma maneira de deixar isso gravado, quando a gente vê que os mais velhos foram embora, daí eu pensei eu tenho um conto, mas se eu não colocar em cordel, livro e tal, aí eu estaria deixando morrer com o tempo, e escrevi 150 cordéis já, acho que a minha coleção está aí, das histórias.

É ainda nesse contexto de transição que Ditão se insere na vida urbana, primeiro em São Luiz do Paraitinga, para continuar os estudos do então ciclo de Primeiro Grau e, depois, em São José dos Campos, centro urbano localizado na Rodovia Presidente Dutra, onde trabalhou na Embraer e cursou ensino técnico do Senai.

Após o ensino técnico, ele opta por retornar ao bairro do Bom Retiro e ao seu sítio, de onde não sairia mais. A vida de sitiante lhe possibilita manter-se na Folia de 
Reis, ao mesmo tempo em que continua colecionando suas histórias, escrevendo versos e ouvindo as músicas sertanejas nas rádios. Porém, a experiência nas cidades influencia uma mudança nas suas atividades de sitiante, que troca a agricultura tradicional pela orgânica e a apicultura, produzindo bens regularmente negociados na cidade.

O crescente envolvimento com a cidade de São Luiz do Paraitinga, de meados da década de 1980 adiante, abre um conjunto de novas interações para Ditão. Nas décadas de 1980 e 90, a cidade é projetada no meio acadêmico e na mídia nacional, como último reduto caipira do estado de São Paulo, com destaque para seu calendário de festas religiosas e o carnaval de marchinhas, além do patrimônio cultural, atraindo investimentos crescentes do mercado turístico. ${ }^{9}$ Novos agenciamentos emergem na cidade, favorecendo o desenvolvimento de um cenário cultural diversificado, no qual Ditão esteve envolvido de várias maneiras: como compositor de marchinhas de carnaval, poeta, contador de "causos" e especialista em cultura caipira.

As interlocuções regulares que se estabelecem entre atores endógenos e exógenos às manifestações culturais da cidade promovem um campo de ressignificação das tradições e memórias locais, que convergem para a expressão de novas ações coletivas. Neste contexto, destaca-se a Associação Sosaci - Sociedade dos Observadores de Saci. ${ }^{10}$ Esta autodenominada Organização Não Capitalista - ONC - surge do encontro de vários intelectuais e agentes culturais da região do Vale do Paraíba e da capital do estado, que frequentavam a cidade e estavam incomodados com os agenciamentos de um "imperialismo cultural" que, segundo os mesmos, descaracterizavam seus traços culturais e tradições. As discussões e encontros promovidos por esses sujeitos tomaram forma de Associação, em julho de 2003, com o objetivo de valorizar a cultura popular e caipira, com foco nas tradições populares locais.

No âmbito das redes de interação em que Ditão já estava envolvido, suas ações foram convergindo para uma aproximação com a Sosaci, devido a ser regularmente reconhecido como um especialista nas manifestações culturais locais pelos integrantes da organização, em contraposição a uma relutância manifestada pela população local.

O começo foi um pouco difícil, um pouco não, muito difícil, porque ainda tem pessoas que falam “ele está falando lá, mas ele está mentindo”.

9 A cidade de São Luiz do Paraitinga tem o maior conjunto de casarões imperiais do estado de São Paulo, o que lhe rendeu o registro de Patrimônio Histórico do Estado em 1982; de Estância Turística, em 2002, e de Patrimônio Cultural Nacional, pelo Iphan, em 2010. Esse patrimônio é complementado pela realização de manifestações tradicionais como o Carnaval de Marchinhas, a Semana Santa, a Festa do Divino Espírito Santo e outras, inscritas no Calendário Cultural do estado e do país, desde a década de 1990. Na década de 2000, vários projetos de agentes culturais locais foram selecionados no Programa Cultura Viva, do MinC, instalando-se Pontos de Cultura que consolidaram um cenário cultural dinâmico na cidade.

10 A Sosaci tem um sítio na web, com sua ata de fundação, um Manifesto do Saci, informações de atividades e galeria de imagens. Disponível em: <https://www.sosaci.org.br/area-para-associados>. Acesso em: 28 ago. 2017. 
Por incrível que pareça, as pessoas de fora reconhecem mais do que as pessoas daqui. Eu sou mais conhecido lá fora. Por exemplo, na Festa do Divino, até saiu uns fogos aí, quando eu estou passando na rua, as pessoas me abordam para falar: "Eu vi as suas poesia e tudo mais", mas a maioria é de fora, quero dizer, são turistas né. E de São Luiz assim, agora que tão começando a reconhecer.

Nesse espaço de ação-reconhecimento, Ditão lançou as bases de seu projeto pessoal, amadurecendo como contador de histórias e escritor de cordel.

[...] foi 2003 , senão me engano, eu me vesti de uma maneira diferente e fui aqui na casa do Osvaldo Cruz e comecei a contar as histórias de lobisomem, aí depois veio o Saci e depois veio todos os mitos, né. E o que que acontecia antes, estava tudo gravado, mas era dificil a gente ser um contador de histórias em São Luiz do Paraitinga, porque é uma cidade misteriosa, mas ao mesmo tempo ela cobra da gente; quero dizer, a população, né, é muito religiosa e conservadora, a gente tinham e do de contar histórias e depois ser crucificado.[...]

E você sabe disso, é você trocar um dedinho de prosa, contar uma história de assombração ou de alguma coisa de mitos, alguém já conta outra em cima, mesmo não acreditando, vem e conta uma aí, então eu percebi, é só você dá um começo que isso aí vai expandir, porque diz que aqui em São Luís tinha duzentos contadores de história. Hoje se resume em quê? Em poucos, quase todos são, mas se não der um incentivo, eles não vão. $\mathrm{E}$ aí eu comecei a registrar isso nos livrinhos. Vou fazer uma história inversa, o primeiro que eu fiz foi "O batizado do Saci".

E o batizado do Saci torna-se também seu batizado em uma nova fase. Através de suas novas interações, Ditão se apropria de referências intelectuais (folcloristas como Câmara Cascudo, Alceu Maynard, e livros de história), fontes da internet, matérias de jornal e televisão, além de estabelecer interações com cordelistas de outras regiões: "Eu tenho muito contato com nordestino que escreve cordel, inclusive em São Paulo tem muitos cordelistas. Aqui na nossa região, no Vale do Paraíba tem muito pouco, aqui em São Luiz acho que nem tem, só eu". No escopo dessas interações e apropriações, passa a escrever cordéis sobre temas variados (história do futebol, tsunamis, lendas indígenas, África, vidas de santos, Zumbi dos Palmares, a Cabanagem, etc. ${ }^{11}$ ), mas sempre os associando com o Saci e outros personagens da cultura caipira. Esses cordéis são publicados em uma gráfica de Taubaté, com apoio que ele angaria de comerciantes de São Luiz do Paraitinga.

Os cordéis que escreve vão se difundindo regionalmente, até que, em 2007, ele escreve um cordel a pedido de atores culturais e políticos locais, que constituem o Movimento em Defesa de Pequenos Agricultores, uma ação coletiva de enfrentamento da expansão da monocultura de eucalipto na região. $O$ cordel ( $O$ saci e o eucalipto) é amplamente

11 A coleção completa dos cordéis escritos por Ditão encontra-se disponível em seu sítio na web. 
difundido por agentes culturais, inclusive por lideranças do Movimento dos Sem Terra MST, em várias regiões do país. ${ }^{12}$

Essa projeção nacional impulsiona também sua trajetória de contador de histórias: Ditão é selecionado, entre vários contadores de história do país, para gravar uma propaganda da Bunge (empresa multinacional dos ramos de agronegócio, alimentos e bioenergia), transmitida em cadeia nacional durante os intervalos do programa Fantástico, da TV Globo. ${ }^{13}$ A partir daí, é selecionado em edital do Programa Griô (Mestres de Saber), do Ministério da Cultura e teve participação em vários filmes, como Mistério da Matriz e Caçadores de Aventura, em mais de 20 documentários e entrevistas sobre o Saci, além de participações em programas de TV como Balanço Geral (TV Record), Coração do Brasil e Pânico da TV (TV Bandeirantes),Vanguarda Mix (Globo) e Sr. BRASIL, com Rolando Boldrin (TV SESC).

Em 2010, Ditão publica outro cordel muito difundido (A enchente do Paraitinga), sobre a enchente do rio que atingiu a cidade de São Luiz do Paraitinga, destruindo vários de seus patrimônios arquitetônicos. Essa difusão crescente de seus cordéis reverte em proveito de seus projetos e legitima suas iniciativas. Em 2007, 2013 e 2015, Ditão teve projetos aprovados nos Editais do PROAC-SP, ${ }^{14}$ respectivamente, publicando um livro (Estórias de uma perna só) e dois audiolivros (Histórias de uma perna só 2 e Histórias Contadas - Lendas e Mitos). Desde o primeiro edital, entretanto, a seleção do seu livro foi condicionada à "tradução" dos textos para o dialeto caipira, pela equipe técnica da Secretaria de Cultura. E essa condição implicaria em um novo aprendizado.

[...] eu pesquisei bastante, em livros, em vários lugares na internet que tiraram lá prá mim e tal. Como eu já tinha experiência de falar assim, caipira assim, a gente vai se juntando, um pouco dos livros, um pouco da gente [...] porque é muito fácil falar caipira, mas muito dificil escrever caipira. Então é uma coisa que você precisa pegar de vários livros, para saber o que a gente tá falando, para não falar bobeira também, quando a gente vai escrever a gente tem que ter base em alguma coisa, que a gente já sabe, mas quer confirmar, tive que devorar livros, aquele que eu não tive na escola, que era aqueles livrinhos lá de governo do Estado e coisa, não tive quase nada, eu fui procurar de outra maneira.

Nesse compasso de aprendizados, as ações e produções de Ditão, mesmo quando referenciadas e protagonizadas pelo Saci, são progressivamente associadas à defesa da natureza, da cultura caipira e do patrimônio cultural.

12 O sítio pessoal de Ditão contém um link para a matéria jornalística sobre esse acontecimento, entre vários outros registros disponíveis, como as participações em documentários e programas de TV.

13 Disponível em: <https://www.asuswebstorage.com/navigate/s/C4873BAC09CC4E36BF16030A85A70FC64>.Acesso em: 20 out. 2017.

14 O Programa de Ação Cultural - PROAC - faz parte de uma política da Secretaria de Estado da Cultura de São Paulo, que financia projetos através de editais. Esta iniciativa de Ditão o projetou, posteriormente, no circuito Revelando São Paulo, outra política da mesma Secretaria da Cultura. 
O segundo quadro de experiência é o de Antônio Olmiro dos Reis, gráfico aposentado, de 68 anos, residente em Canela, ${ }^{15}$ RS, e colecionador de vários objetos: fotografias antigas de Canela, revistas, livros, rótulos de cachaça, cartões telefônicos, entre outros.

A experiência colecionista de Olmiro começa em sua infância. Conforme seu depoimento, ${ }^{16}$ quando recebia algum dinheiro de seu pai, fazia questão em ir a um estabelecimento comercial próximo a sua residência comprar balas que traziam diversas figuras estampadas.

[...] quando eu era guri, que eu era pequeno, o pai, nos domingos, dava uns 'níqueis' prá gente e a gente ia comprar umas balinha ali na João Pessoa, ali no boteco tinha. E quando eu pegava aquela balinha eu ficava imaginando, que interessante, como é que podem imprimir isso? De certo já estava escrito que um dia eu ia ter uma gráfica, mas, que interessante, né. E aí bem lá no início dos anos 50 surgiu uma bala que tinha uma figura e é uma historieta cortada assim como se fosse um desenho, né. E essas eram as balas do Brocoió. Era uma espécie assim, de Popeye brasileiro, sabe?

Aquela primeira dezena de figurinhas foi guardada e, na época, colada em um caderno. Na adolescência, a partir de outras redes de sociabilidade, desenvolveu o gosto pela leitura e começou a adquirir revistas.

Eu lia muita revista em quadrinhos, né. Qualquer troco que eu tinha assim, eu deixava de ir ao cinema ou à matinê à tarde para poder comprar uma revista usada e ler aquela revista e poder trocar por outra assim, né. Então, depois da revista, ali com 13,14 anos eu passei já a ler literatura universal.

Associado às mudanças em seus ciclos de vida (Lopes, 2017), o interesse de Olmiro em colecionar vai se diversificando e as práticas de colecionismo vão assumindo contornos mais consistentes. Da infância à adolescência, evidencia ter aprendido duas práticas colecionistas, a saber: guardar e trocar. Aos 18 anos, começa a trabalhar e, com seus primeiros salários, compra uma máquina fotográfica ("uma caixãozinho”, em seus termos) e passa a fotografar a cidade (Canela) e o bairro onde residia (Vila Boeira). $\mathrm{O}$ aprendizado da fotografia torna-se condição para mobilizar-se a colecionar imagens sobre Canela.

Aí, foi a própria história de Canela, foi, sem querer, eu comecei a pedir fotos emprestadas para os vizinhos, de reprodução, cada foto era praticamente uma história, né. Então, eu comprei um caderno de cem páginas e pedia para eles, de letra própria, de próprio punho escrever no caderno o que eles quisessem,

15 Cidade localizada na região da serra gaúcha, cerca de $120 \mathrm{~km}$ da capital do estado, Porto Alegre, e $6 \mathrm{~km}$ da cidade de Gramado. Atualmente, o município conta com 39.229 habitantes, segundo informações do sítio oficial da Prefeitura Municipal. Disponível em: <http://www.canela.rs.gov. br/index.php/cidade>. Acesso em: 19 set. 2017.

16 A entrevista com o Senhor Antônio Olmiro dos Reis foi realizada em julho de 2013, em seu escritório localizado na gráfica de propriedade de sua família, em Canela, RS. 
de livre e espontânea vontade. Quando eu fazia perguntas, mais ou menos eu perguntava 'ah, e quando o senhor veio morar em Canela, quais eram as famílias que existiam?'. Aquilo ajudava a me localizar, sabe. Que lá, então, um cara 'ah, eu cheguei em 40', e 'qual é as casas que já tinham?' Ou se o cara dizia 'eu cheguei em 20', o que é que já existia e assim que eu... eu perguntava o seguinte: como é que eram os colégios, o salão de baile, tudo assim do dia-a-dia né. Eu me foquei muito assim em fotos de rua para poder, então... Quando eu vi, daí eu já tinha um acervo.

Com as imagens, Olmiro inicia visitações às famílias, mediante conversações informais, interpelando-as sobre as condições em que as fotografias foram realizadas. Quem eram os fotografados? Qual o lugar? Qual o ano aproximado? Anotava essas informações no verso ou em um caderno e, aos poucos, foi reunindo um grande acervo. Em 1983, realizou a primeira exposição com as fotos que foi recebendo de mais de cem famílias da cidade. Além de colecionador, torna-se um memorialista.

Olmiro vai, paulatinamente, elaborando um conjunto de outras coleções que se associam às memórias sociais de Canela. Por um lado, então, as coleções foram aumentando e se complexificando.

Ah, isso foi assim, por exemplo, tu vai 'ah, mais para que Miss Brasil?, ah Miss Brasil é um concurso que'... Teve uma canelense né, que foi Miss Brasil em 86, a Deise Nunes. A partir daquela época eu me interessei em colecionar também é, as misses, aí eu pensei’ bom, já que eu coleciono Miss Brasil, vou colecionar Miss Universo também já que sai nas revistas, assim todos os anos as candidatas, né, as que vencem. Aí eu fazia reprodução, então 'scanneava', eu tenho todas elas assim. É o mesmo sistema. Em cada folha A4 eu tenho separadinho, um de cada só, né. Mas é porque eu procurei sempre pegar coisas que levem Canela para vitrine ou sei lá, que lembram a cidade, né. E quando não, acho que é mania mesmo, é com prazer assim.

Chegou a ter, ao mesmo tempo, 11 coleções. Suas coleções são feitas, predominantemente, por doações. A diversificação dos motivos das coleções o fez inserirse em redes de colecionadores, em escala nacional e internacional, bem como a uma rede de interlocuções e parcerias com outros memorialistas e colecionadores em escala local.

Tudo, tudo, tudo que eu, por exemplo se eu ganho um cartão postal, vamos supor assim, de estádio de futebol, e eu coleciono, aí eu mando para quem coleciona. Eu sou associado em Brasília na Associação Filatélica e Numismática que abrange mais de mil colecionadores em todo o mundo. Tem associados aqui da América, dos Estados Unidos e da Europa. Então nós temos uma [...], é uma grande confraria que se troca correspondências. Então a gente, tu escreve para um ele já 'ah, eu tenho amigos lá no Japão que te consegue isso aí'. É assim que funciona. É tudo, dificilmente tu compra, é tudo dado, né. 
A cidade de Canela é a motivação principal de sua atividade colecionista. No entanto, frente à diversificação do material, utiliza diversos critérios ou princípios para a organização do acervo.

A história de Canela, que é a principal coleção minha, eu organizo em ordem de data. Eu não achei outra forma. O rótulo de cachaça, eu separo tudo por assunto, aqui: rótulo de cachaça só do Rio Grande do Sul, por exemplo. Depois, assim: passarinho com passarinho, mulher com mulher, por temas. E dentro cada estado. Eu tenho assim, quase três mil rótulos, todos separados por tema e dentro de estados.

Interessante observar que as coleções de Olmiro desenvolvem-se no contexto de inserção das cidades de Canela e Gramado no circuito econômico do turismo nacional. Há, no contexto regional, uma progressiva expansão da especulação imobiliária e, com efeito, a comercialização de imóveis de antigos moradores a incorporadoras e investidores do mercado imobiliário. ${ }^{17}$ Parafraseando Walter Benjamin (1994), as experiências transmitidas de geração em geração vão declinando e empobrecendo, na mesma razão em que a paisagem vai sendo transformada de modo acelerado.

O trabalho de colecionador vai se diversificando e assumindo a forma de memorialista e cronista. Como relata em depoimento à Prefeitura Municipal de Canela, o colecionador, quando jovem, "sentia curiosidade em saber mais sobre o passado de Canela. Só se falava em história da América, do Brasil e um pouco do Rio Grande do Sul na escola, mas nada da localidade" 18 . Escreveu, primeiramente, em coautoria com outros dois memorialistas da cidade, o livro "Canela por muitas razões". Por décadas, escreveu uma coluna de memórias para o Jornal Nova Época, de circulação local, as quais foram organizadas, sistematizadas e apresentadas na forma de livro, "Canela passado a limpo", publicado em 2014. Esta obra contou com apoio da iniciativa privada e obteve financiamento da Secretaria Estadual de Cultura, através da Lei de Incentivo à Cultura do Estado (LIC/RS).

O trabalho de Olmiro como cronista aproxima-se da elaboração de Walter Benjamin sobre o lugar e o trabalho do narrador, em sociedades onde vislumbra-se a "pobreza da experiência" (Benjamin, 1994). Segundo o filósofo, a arte de narrar estaria em vias de extinção, no começo do século passado, pois “são cada vez mais raras as pessoas que sabem narrar devidamente" (Benjamin, 1994, p. 197). A capacidade de intercambiar experiências torna-se limitada e nos tornamos, sobretudo após a Primeira Guerra, "mais pobres em experiência comunicável" (Benjamin, 1994, p. 198).

A fonte viva dos narradores é a experiência transmitida entre as gerações. "O narrador retira da experiência o que ele conta: sua própria experiência ou a relatada

17 Essa situação motivou outros moradores da cidade a também colecionarem e exporem imagens de casas e edificios antigos, e suas transformações, como é o caso de Norberto Geraldi, que mantém o blog Canela RS - Fotos históricas. Disponível em: <http://ngc44-canelafotos1.blogspot.com. br/2013/04/1940-hotel-bela-vista.html\#.WcFjqYRe7IU>. Acesso em: 19 set. 2017.

18 Disponível em: <http://www.canela.rs.gov.br/index.php/noticias/592-antonio-olmiro-dos-reis>. Acesso em: 04 set. 2017. 
pelos outros. E incorpora as coisas narradas à experiência de seus ouvintes" (Benjamin, 1994, p. 201). No caso das narrativas de Olmiro, evidencia-se as circunstâncias do tempo histórico em que a fotografia foi produzida e, a partir desta, passa a narrar elementos da memória relatados pelo indivíduo ou pela família que emprestou a figura. Suas crônicas fazem circular narrativas de temporalidades diversas, uma vez que "o cronista é o narrador da história" (Benjamin, 1994, p. 209). Nesse momento, Benjamin diferencia o trabalho do historiador e o do cronista, sendo que o primeiro se responsabiliza pela escrita da história, enquanto que o segundo com a narração. $O$ historiador é obrigado a explicar e enquadrar os episódios que estuda em modelos universais. Para o narrador, a memória é imprescindível.

Além da preocupação com a narração das memórias da cidade, Olmiro doou parte significativa de sua coleção de fotografias ao Centro de Memória do Trabalho de Canela, organizado pelo Sindicato dos Metalúrgicos. O gesto evidencia-nos uma preocupação com a institucionalização de "lugares de memória" (Nora, 1993) no contexto urbano, onde reside, sobretudo no contemporâneo, quando observamos o esgotamento e o colapso das grandes memórias organizadoras (Candau, 2016).

Contudo, mantém exposições regulares em pontos turísticos da cidade ou quando convidado para eventos na região. Nosso interlocutor segue recebendo documentos e fotografias.

Tu não imagina o que eu tenho de documento, que eu ganho das pessoas, elas colocam dentro de envelopes e colocam de baixo da porta 'ah, o Olmiro que gosta de coisas velhas'. E ali vem documentação de pessoas que eu nunca vi na minha vida, mas que provavelmente foram os netos que deixaram ali, né? Ou os próprios catadores de papel na rua, eles me ajudam muito. É de quem eu menos espero que venha as ajudas, sabe?

Como costuma relatar, recebe diversos materiais em doação, algumas dessas de modo anônimo, outras doações chegam com alguns bilhetes ou informações difusas. Há, no imaginário local, uma associação “da pessoa de Olmiro” às suas coleções e ao seu projeto de memorialista. Relatou-nos que, em recente diálogo com uma ex-Secretária Municipal de Educação, a mesma referiu-se ao colecionador como "guardião da memória de Canela".

É, agora eles me chamam de guardião da memória de Canela. Mas nem existe, foi a Berenice Felipetti que disse, 'bah Olmiro, tu é o guardião das fotos de Canela, da nossa memória, né'.

Assim, é justamente nessa trama biográfica e social que o tem constituído como colecionador, memorialista e cronista, que sua preocupação com as memórias da cidade encontra sentido e representatividade. 


\section{Considerações finais}

Diante desses quadros de experiência, alguns aspectos se destacam para análise. $\mathrm{O}$ início das práticas de colecionamento, nos dois casos, se expressa como um propósito de materialização de histórias ou objetivação das memórias locais. Ditão aprendeu, desde cedo, que essa objetivação se faz como projeto:

Entrevistador: O que seu trabalho de contador de histórias e escritor de cordel tem a ver com a cidade de São Luiz do Paraitinga?

Ditão: Como eu nasci e me criei aqui em São Luiz do Paraitinga, muitas histórias daqui, de lembrar do pessoal que contava história, uma das coisas que fica marcada é a história oral, e dever os velhos contadores de história que se foram, ela tem tudo a ver com a memória de São Luiz, porque São Luiz ela é toda ligada com essa coisa dos mitos, e também da própria história da cidade, eu acho que tem tudo a ver. [...] Assim, depois que comecei pensei um projeto: vou fazer 365 livros de cordel, uma história para cada dia do ano.

Já Olmiro configura seu projeto desde quando o interesse pelos objetos, aos poucos, desloca o sentido de suas motivações para fora de si, até elas se generalizarem em um registro coletivo. $\mathrm{Na}$ experiência de colecionador, isso foi ocorrendo devido à mudança dos valores expressos na própria trajetória das coleções, que resultou na constituição de um acervo.

Eu acho que o valor é sempre [...] é cada vez maior, porque aumenta o acervo, né? E por exemplo, eu comecei só com fotos. Daí eu senti a necessidade de historiar essas fotos. [...] eu descobria que numa cidade do interior, por exemplo lá no Paraná, tinha um ex-morador de Canela e eu ia atrás. Daí uma vez eu fui do lado de Blumenau, numa cidade lá, eu descobri que um exfotógrafo de Canela, dos anos 1950, 60, estava morando perto de Blumenau. E o meu filho mais novo, que hoje é piloto, ele tinha um encontro de, como é que se diz [...] aeromodelismo. Na cidade de Gaspar, ali em Santa Catarina. E esse senhor morava ali em Gaspar, do lado, ali. E á enquanto meu filho ficou lá no centro o dia todo, eu fui conversar com esse senhor. Ele morava lá e ele ainda tinha os negativos de todas as fotos que ele tirou da região aqui. Isso faz parte da história de Canela.

Nesse sentido, a aprendizagem de um projeto explicita como o valor que sobressai das objetivações do espírito nasce da consciência subjetiva, mas vai além dela, adquirindo um fundamento e um direito (o sentido cultural do objeto), em agrupamentos de coisas específicas, acrescendo "o universo das coisas que têm um certo valor" (Simmel, 2005, p. 84) coletivo. Segundo este autor,

[...] isto constitui uma diretriz de nossas formas de atribuir valor. [...] na existência própria do que é espiritual-objetivo, sem, para além do que é definitivo nestas próprias coisas, questionar suas consequências no plano da 
alma [...] consideramos um valor de tipo especial o fato dela [uma obra] existir, o fato de o espírito ter criado para si este recipiente.

E se o universo das coisas que tem um certo valor coletivo é cultural, em Ditão este universo se expressa nas representações do mundo rural, caipira, que desde criança percebeu nas paisagens que habitou e nas histórias e músicas que leu e ouviu em versos. Assim, essa longa formação como colecionador se projeta também em um longo projeto de objetivação.

Isso já está bem adiantado, eu adiantei porque que falei, eu es tava fazendo a conta, eu estava meio devagar e aí eu teria que viver 100 anos para escrever esses 365, porque eram tantos por ano, e agora dei uma adiantada, não é bem um cordel daqueles dos 32 versos, mas já dá, já tem 300 poesias escritas.

Entrevistador: E depois que você publicar esses?

Ditão: Daí eu quero fazer o 366, que é do ano bissexto.

Entrevistador: E depois do 366?

Ditão: Daí vamos chegar em uns 500, vamos tentar começar de novo, vamos dobrar isso dá, fica dois por dia do ano, dá para copiar, por exemplo, um é o batizado do saci, e o outro é a desistência do saci, depois o encontro com o saci, depois desencontro como saci, e por aí vamos, é nunca parar.

Por sua vez, esse longo projeto de objetivação pode se desdobrar em outras formas culturais.

[...] quando eu comecei a escrever cordel, eu vinha para a cidade, chegava aqui e tinha os cordéis nordestinos que eram vendidos numa lojinha que tem ali perto da igreja. Aí eu lia muito cordel nordestino, eu gosto. Nossa, é muito legal, mas tem muitas regras. Até eu criei, eu não sei se posso dizer que eu criei, porque já vem, nós criamos, os contadores de histórias, eu não gosto de falar o eu, nós criamos o cordel caipira. Porque aí já fala de uma maneira diferente, e como ele foi criado eu tinha projetos de se, um dia, porque muitas vezes ele nem é aceito como cordel, um dia reconheça que seja um tipo de cordel, um cordel diferente, que é um cordel caipira.

[...] eu estou fazendo um projeto agora como Cabran, ele vai fazer pinturas diferentes do tipo gravura, entendeu?

[...] um dos livros que eu ganhei até o projeto do PROAC era nas cabaças né, então precisa ter um certo cuidado de não ficar só em uma coisa. Então, quando você falou em projeto, essa seria uma das coisas a ser discutido, para fazer um projeto. Vai dar muita polêmica, porque não tem que ser como antigamente, as minhas histórias são como antigamente, mas os meus livrinhos não.

[...] E usar nas escolas.É uma coisa que poderia ser passado nas escolas, "você lê esse versinho, e amanhã ou depois ou quando for, vem aqui e declama ele, sem ler". Eu acho muito legal, por exemplo, muito bom, as pessoas chegarem 
e já falar abertamente, sem precisar ficar lendo, eu vejo muito artista que bota a letra no chão e fica lá olhando, aí perde esse negócio da voz que eu falei e perde também a interpretação, o jeito do corpo. Entendeu como é o negócio?

De forma semelhante, no caso de Olmiro, o reconhecimento de formação de um acervo logo se projetou em projetos de exteriorização (publicização) do mesmo. Nesse sentido, realizou exposições e passou a escrever uma coluna em um jornal da cidade.

[...] em 1983 eu realizei a primeira mostra fotográfica de Canela e eu guardei uma relação que fiz. Eu convidei cento e vinte e três pessoas para essa mostra. Tu vê que eu já tinha ido em cento e vinte e três famílias em 83.

[...] eu escrevi durante cinco anos no Jornal, e desses cinco anos, é o livro que está pronto. Tive coluna no jornal, né? Daí em 2008 eles acabaram com os colunistas. Eles tinham um caderno especial assim, só de colunistas, assim como a Zero Hora em domingos tem aquele caderno Donna, eles fizeram um caderno de colunistas. Aquilo funcionou durante muitos anos, daí em 2008 eles resolveram mudar o sistema do jornal.

Ocorre aqui uma lógica de representação que justifica e legitima os projetos dos colecionadores. Ainda segundo Simmel (2005, p. 86): "não há nenhum valor de cultura que seja apenas valor de cultura; cada um precisa antes, para alcançar esta significação, ser também valor em uma série objetiva". A constituição dessa série objetiva de valor, nas atividades ou bens culturais, se produz na medida em que as próprias obras do sujeito dialogam com as representações de seu tempo biográfico e social, de sua trajetória, de forma que a ideia de cultura se encontra em meio a um dualismo: fundamenta-se em um fato interior e se expressa em um fato objetivado, inanimado; o que é inanimado possui um presente, enquanto o ser vivo estende-se ao passado e ao futuro (Simmel, 2005, p. 79).

Todavia, torna-se necessário entender que a obra objetivada, inanimada, possui um presente atemporal para Simmel, que ultrapassa a finitude humana de quem a cria. Dessa forma, a objetivação perpetua a obra quando a significação daquela série objetiva de valor adquire legitimação coletiva. Isso implica que toda significação de uma obra cultural se inscreve em um regime de valor (Appadurai, 2008), ou é estabelecida segundo o "diagnóstico de uma política de significância na qual muita coisa depende do que se considera importante e do que é relegado ao limbo do "meramente"" (Herzfeld, 2008, p. 10).

E é nesse processo de inscrição das obras em regimes de valor que as memórias coletivas sofrem modulações, segundo as trajetórias dos sujeitos são marcadas por interações necessárias à legitimação que sustenta seus projetos. 


\section{Referências}

APPADURAI, Arjun. Mercadorias e a política de valor. In: APPADDURAI, Arjun (Org.). A vida das Coisas: as mercadorias sob uma perspectiva cultural. Niterói, RJ: EdUFF, 2008. p. 15-88.

ASSIS, João Marcus Figueiredo Assis. Arquivos: produções e reapropriações de sentidos. Observatório Itaú Cultural, São Paulo, n. 22, p. 45-54, maio/nov. 2017.

BENJAMIN, Walter. O narrador - Considerações sobre a obra de Nikolai Leskov. In: BENJAMIN, Walter. Magia e técnica, arte e política: ensaios sobre literatura e história da cultura. 7. ed. São Paulo: Brasiliense, 1994. p. 197-221.

CANDAU, Joel. Memória e identidade. São Paulo: Contexto, 2016.

CERTEAU, Michel de. A invenção do cotidiano. Petrópolis, RJ:Vozes, 1994. (v. 1: Artes de fazer).

GOFFMAN, Erving. Os quadros da experiência social: uma perspectiva de análise. Petrópolis, RJ:Vozes, 2012.

HERZFELD, Michael. Intimidade cultural: poética social no Estado-nação. Lisboa: Edições 70, 2008.

KOPYTOFF, Igor. A biografia cultural das coisas. In: APPADURAI, Arjun (Org.). A vida social das coisas; as mercadorias sob uma perspectiva cultural. Rio de Janeiro: EdUFF, 2008. p. 89-121.

KUHN, Thomas. A estrutura das revoluções científicas. São Paulo: Perspectiva, 1983.

LE GOFF, Jacques. História e memória. Campinas, SP: Editora da Unicamp, 1996.

LIMA FILHO, Manoel Ferreira. Cidadania patrimonial. Anthropológicas, Rio de Janeiro, Ano 19, v. 16, n. 2, p. 134155, 2015.

LOPES, José Rogério. Colecionismo, arquivos pessoais e memórias patrimoniais. Porto Alegre: Cirkula, 2017.

Deus Salve Casa Santa, Morada de Foliões. Rito, Memória e Performance Identitária em uma Festa Rural no Estado de São Paulo. Campos, Curitiba, v. 8, n. 1, p. 125-144, 2007.

NORA, Pierre. Entre memória e história: a problemática dos lugares. Projeto História, v. 10, p. 7-28, 1993.

SILVA, Rodrigo Manuel Dias da. Educação patrimonial e políticas de escolarização no Brasil. Educação E Realidade, Porto Alegre, v. 41, n. 2, p. 467-489, abr./jun. 2016.

Educação patrimonial e a reconstrução de manifestações expressivas: imagens de Laguna, SC. Memória em Rede, Pelotas, RS, v. 8, n. 14, p. 159-168, jan./jun. 2016a.

SIMMEL, Georg. O conceito e a tragédia da cultura. In: SOUZA, Jessé; Öelze, Berthold (Org.) Simmel e a modernidade. 2. ed. Brasília: EdUNB, 2005. p. 77-106.

VANVELSEN, Jaap. A análise situacional e o método de estudo de caso detalhado. In:

FELDMAN-BIANCO, Bela (Org.). Antropologia das sociedades complexas - Métodos. São Paulo: Global, 1987. p. 345-372.

VELHO, Gilberto. Individualismo e cultura; notas para uma antropologia da sociedade contemporânea. 2. ed. Rio de Janeiro: Jorge Zahar, 1987.

YÚDICE, George. A conveniência da cultura; usos da cultura na era global. Belo Horizonte: Editora UFMG, 2006. 


\title{
Collectors and patrimonial citizenship: file assemblies in local memorialist projects
}

\begin{abstract}
The article discusses the memorialist demands of private collectors designed in the political agendas of cultural patrimonialization, in situational approach. Since the description of two cases of collecting - one in Canela, RS, Brazil; other in São Luiz do Paraitinga, SP, Brazil -, were considered the strategies and tactics operated by collectors, aiming at the formation of personal files, your scanning and the assemblages on the collective memories, from the perspective of cultural citizenship. This approach involves considering the collections as social goods that produce modulations in the collective memories, sites for establishment of discursive regimes and regimes of value. This occurs in singling out negotiated processes in networks of interaction of the collectors, or in processes of institutionalization of the collections in "memorialist devices", such as publications and memory centers.
\end{abstract}

Keywords: Collectors, patrimonial citizenship, files, memories, assemblages.

\section{Coleccionistas y ciudadanía patrimonial: los agenciamientos de archivos personales en proyectos memorialistas locales}

\section{Resumen}

El artículo discute las demandas memorialistas de coleccionistas privados proyectadas en las agendas políticas de patrimonialización cultural, en un abordaje situacional. A partir de la descripción de dos casos de coleccionismo - uno en Canela, RS, otro en São Luiz do Paraitinga, SP, ambos en Brasil -, se consideran las estrategias y tácticas llevadas a cabo por los coleccionistas, procurando la formación de archivos personales, su digitalización y sus vinculaciones con las memorias colectivas, desde la perspectiva de la ciudadanía patrimonial. Este enfoque conlleva considerar las colecciones como bienes sociales que producen modulaciones en las memorias colectivas locales, por el establecimiento de regímenes discursivos y regímenes de valor, o en procesos de singularización negociados en las redes de interacción de los coleccionistas, en procesos de institucionalización de las colecciones en "dispositivos memorialistas" públicos, como publicaciones y centros de memoria.

Palabras clave: Coleccionistas, ciudadanía patrimonial, archivos, memorias, agenciamientos. 